\title{
Mammary Myofibroblastoma in a Transgender Patient on Feminizing Hormones: Literature Review and Case Report
}

\author{
Jane O'Bryan,, ${ }^{1, *}$ Carolyn Wolf-Gould, ${ }^{2}$ and Yoshiro Matsuo ${ }^{3}$
}

\begin{abstract}
Purpose: Defining the risk of neoplasia associated with gender-affirming hormone therapy (GAHT) is a priority for transgender medical research. The purposes of this article are to present a unique case of breast neoplasia in a transgender individual and to review the existing evidence base on GAHT as a potential risk for breast pathology. Methods: We present the case of a 76-year-old transgender patient who developed an estrogen receptorpositive mammary myofibroblastoma (MFB) after 13 months of treatment on feminizing hormones. To our knowledge, this is the first reported case of MFB occurring in a transgender individual. A literature review was conducted to identify all reported cases of breast neoplasia among transgender individuals receiving feminizing GAHT. Information was abstracted from each of the included cases to describe the existing body of literature and to compare published cases to the case reported in this study.

Results: We identified a total of 19 malignant and 3 benign cases of breast neoplasia among transgender women. Ours is the first reported case of MFB in a transgender individual receiving feminizing hormones and the first reported case of breast neoplasia associated with GAHT administered via the estradiol patch.

Conclusion: This case reinforces the need for additional reporting of breast neoplasia presenting in transgender individuals treated with feminizing hormones. The relationship between estrogen exposure and breast neoplasia in the transgender population remains poorly defined, and additional research is needed to define risks and inform clinical practice.
\end{abstract}

Keywords: breast neoplasms; hormones; myofibroblastoma; transgender adult

\section{Introduction}

The relationship between long-term estrogen exposure and the risk of breast neoplasia in transgender people receiving feminizing hormones remains poorly understood. Cisgender women on hormone replacement therapy have increased risks for incident and fatal breast cancers, ${ }^{1,2}$ and clinicians have questioned whether this association can be extrapolated to transgender individuals on feminizing hormone regimens. In particular, clinicians have concerns about the potential of exogenous estrogens to induce estrogen receptor (ER)-positive breast pathologies. Current evidence is insufficient to clearly define this risk and inform clinical practice.
Lifetime breast cancer risk among cisgender males in the United States is $\sim 1$ in $1000{ }^{3}$ Cancers of the breast account for fewer than $1 \%$ of all cancers affecting this population, and make up fewer than $1 \%$ of all breast cancer cases occurring in the United States. ${ }^{4}$ Lifetime breast cancer risk among transgender persons receiving feminizing gender-affirming hormone therapy (GAHT) has not been well defined.

There are only 22 reported cases of transgender patients on feminizing hormones who developed breast neoplasia (Tables 1 and 2). We present a case of a transgender patient diagnosed with an ER-positive mammary myofibroblastoma (MFB) following 13 months

\footnotetext{
${ }^{1}$ Bassett Healthcare/Research Institute, Cooperstown, New York.

${ }^{2}$ The Gender Wellness Center/Susquehanna Family Practice, AO Fox Hospital/Bassett Healthcare Network, Oneonta, New York.

${ }^{3}$ Department of Hematology/Oncology, AO Fox Hospital/Bassett Healthcare Network, Oneonta, New York.
}

*Address correspondence to: Jane O’Bryan, MPH, Bassett Healthcare/Bassett Research Institute, 1 Atwell Road, Cooperstown, NY 13326-1301, E-mail: jane.obryan@yale.edu 


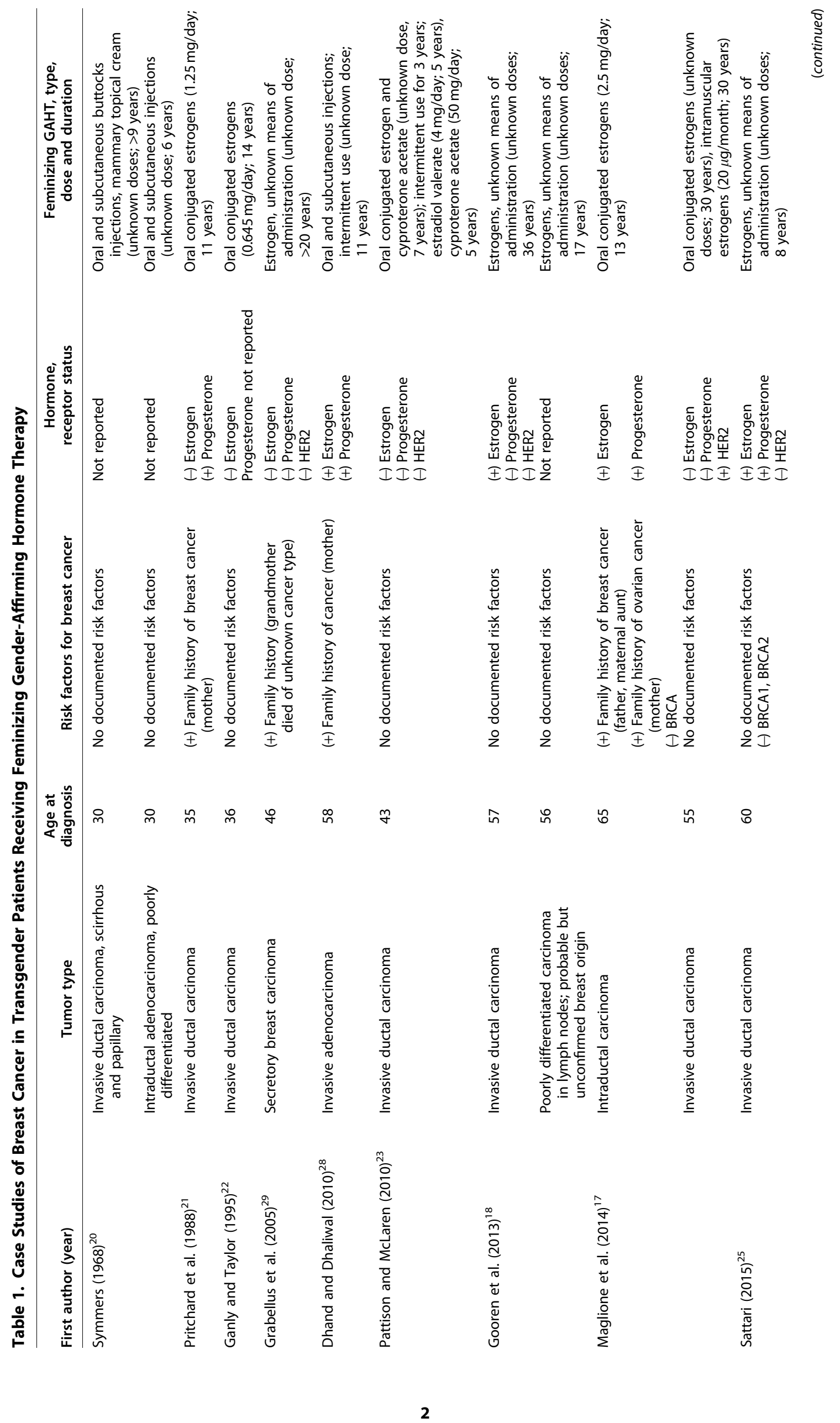




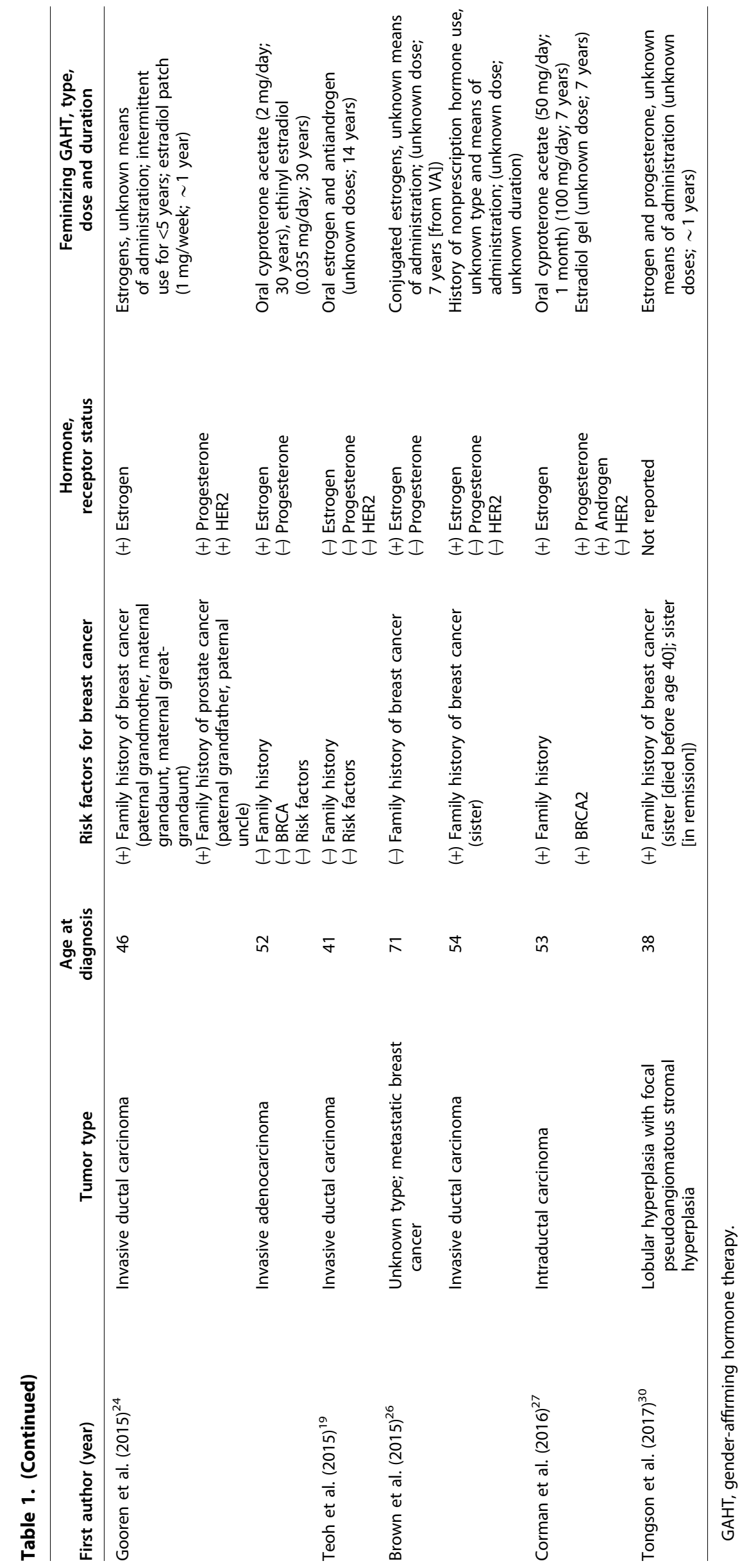


Table 2. Case Studies of Benign Breast Neoplasia in Transgender Patients Receiving Feminizing Gender-Affirming Hormone Therapy

\begin{tabular}{|c|c|c|c|c|c|}
\hline $\begin{array}{l}\text { First author } \\
\text { (year) }\end{array}$ & Tumor type & $\begin{array}{l}\text { Age at } \\
\text { diagnosis }\end{array}$ & $\begin{array}{l}\text { Risk factors } \\
\text { for breast cancer }\end{array}$ & $\begin{array}{l}\text { Hormone, } \\
\text { receptor status }\end{array}$ & $\begin{array}{l}\text { Feminizing GAHT, type, } \\
\text { dose, and duration }\end{array}$ \\
\hline $\begin{array}{l}\text { Kanhai et al. } \\
\qquad(1999)^{31}\end{array}$ & Fibroadenoma & 41 & $\begin{array}{l}\text { No documented risk } \\
\text { factors }\end{array}$ & Not reported & $\begin{array}{l}\text { Oral cyproterone acetate ( } 50 \mathrm{mg} / \text { day; } \\
\quad 19 \text { years) } \\
\text { Ethinyl estradiol ( } 0.1 \mathrm{mg} / \text { day; } 19 \text { years) }\end{array}$ \\
\hline $\begin{array}{l}\text { Lemmo et al. } \\
\qquad(2002)^{32}\end{array}$ & Fibroadenoma & 35 & $\begin{array}{l}(-) \text { History of cancer } \\
\text { (patient) }\end{array}$ & Not reported & $\begin{array}{l}\text { Oral cyproterone acetate (unknown dose; } \\
13 \text { years) } \\
\text { Ethinyl estradiol (unknown dose; } 20 \text { years) }\end{array}$ \\
\hline $\begin{array}{l}\text { Walsh et al. } \\
\qquad(2014)^{33}\end{array}$ & Angiolipoma & 61 & $\begin{array}{l}\text { No documented risk } \\
\text { factors }\end{array}$ & Not reported & $\begin{array}{l}\text { Unknown type, unknown means of } \\
\text { administration (unknown dose; } 18 \text { months) }\end{array}$ \\
\hline $\begin{array}{l}\text { O'Bryan et al. } \\
\text { (2018) }\end{array}$ & Myofibroblastoma & 76 & $\begin{array}{l}\text { (-) Family history } \\
\text { (+) Risk factor for cancer } \\
\quad \text { [former smoker] }\end{array}$ & $\begin{array}{l}(+) \text { Estrogen } \\
(+) \text { Progesterone }\end{array}$ & Estradiol patch (100 mcg/day; 13 months) \\
\hline
\end{tabular}

of estrogen therapy. To our knowledge, this is the first case of MFB reported in this population.

MFB is a rare, benign tumor, presenting in both male and female assigned patients (age range: $25-87){ }^{5-7}$ MFB is classified as a mesenchymal tumor, morphologically similar to tumors occurring in soft tissues as well as the breast, and defined as a "spindle cell tumor of the mammary stroma, composed of myofibroblasts." 8 Typically it presents as a slow growing, solitary mass of less than $4 \mathrm{~cm}$ (range 1.0-3.7), ${ }^{8,9}$ although larger tumors have been documented. ${ }^{8,10}$ The term myofibroblastoma was first used by Wargotz et al., who described a benign tumor occurring most commonly in elderly men, and histologically composed of spindled or oval cells arranged in fascicles separated by bands of collagen and adipocytes. ${ }^{9}$ There are multiple variants of MFB, including cellular, epithelioid, myxoid, fibrous, lipomatous, deciduoid-like, and infiltrative. ${ }^{11,12} \mathrm{MFB}$ is typically treated with surgical excision and relapse is unlikely with free resection margins. ${ }^{13}$ Steroid hormones and their receptors may be linked to the pathogenesis of MFB, with variable expression of tumor markers on pathologic specimens. ${ }^{9,14-16}$ The rapid development of a rare MFB in an elderly transgender patient receiving estrogen therapy raises questions about the risks of ER-positive neoplasia in this population.

\section{Case Report}

A 76-year-old birth-assigned male presented to a gender clinic requesting feminizing hormones. He identified as a cross-dresser and requested masculine pronouns. The patient stated that he had wanted feminizing hormones for over 40 years, but had not felt free to pursue treatment until retirement. He had recently undergone facial feminization surgery. He had also requested breast augmentation, but was advised by his surgeon to try hormones first.
The patient came with a gender assessment from a qualified gender therapist, who attested that the patient met Diagnostic and Statistical Manual of Mental Disorders, fifth edition (DSM-5) criteria for Gender Dysphoria and recommended feminizing hormones. The patient's medical history was significant for hypertension, hypercholesterolemia, benign prostatic hypertrophy, depression, hearing loss, and lumbar disc disease. His medications included aspirin (81 mg/day), gabapentin (100 mg TID), atorvastatin $(10 \mathrm{mg} /$ day $)$, fenofibrate $(160 \mathrm{mg} /$ day $)$, atenolol $(25 \mathrm{mg} /$ day $)$, amlodipine $(10 \mathrm{mg} /$ day $)$, tamsulosin ( $0.4 \mathrm{mg} /$ day), simvastatin $(20 \mathrm{mg} /$ day $)$, lisinopril $(40 \mathrm{mg} /$ day), and fluoxetine ( $30 \mathrm{mg} /$ day). He had no known drug allergies. He was a former smoker (quit 40 years previously), acknowledged rare alcohol use and denied drug use. His family history was significant for a father who died from an unknown alcohol use disorder complication at age 85 and a mother who died of a brain aneurysm at age 71 . The patient had no family history of breast cancer. He had no prior use of feminizing hormones.

Physical examination was unremarkable with the exception of extensive scars from recent facial surgery. He presented as male and there were no breast masses or gynecomastia. His initial laboratory workup revealed a serum testosterone of $291 \mathrm{ng} / \mathrm{dL}$ and normal complete blood count, chemistry panel, and cholesterol profile.

The patient was started on spironolactone $(100 \mathrm{mg} /$ day) and an estradiol patch $(100 \mathrm{mcg} /$ day $)$. The patient followed up after 4 months. In the interim, he had a hair transplant and developed hyperkalemia postoperatively, resulting in discontinuation of spironolactone. He was pleased with breast growth at this visit and his estradiol patch dose was increased to $200 \mathrm{mcg} /$ day. He next followed up after 13 months on GAHT. A complete physical examination was performed, which revealed 
significant breast development but no masses. The patient was referred for a mammogram at this visit, which detected a 6-mm hypoechoic mass at the 7:00 position in the right breast.

The patient was referred to a breast surgeon and had an ultrasound-guided core biopsy of this solid nodule. Pathology revealed a partly grayish white fibrous and partly fatty breast tissue aggregating to about $0.3 \times 1.5 \times 1.8 \mathrm{~cm}$, suggestive of myofibroblastoma. The specimen was sent to an oncological laboratory for further study. This second report described the lesion as consisting of spindle to oval neoplastic cells forming short fascicles with a collagenous stroma.

Cytologic atypia was minimal. The morphological features and positive reactivity for CD34, desmin, and smooth muscle myosin (SMM) supported the diagnosis. Immunohistochemical slides were SMM focal-positive, PanCK-negative, p63-negative, and E-cadherin-negative. The physician requested breast prognostic marker analysis, which indicated 97.71\% ER expression and $93.20 \%$ progesterone receptor (PR) expression with intermediate to strong nuclear staining. Androgen receptor results showed positive, moderate to strong nuclear staining in $>95 \%$ of tumor cells. Postoperatively, the patient saw an oncologist who noted that this was a benign tumor and felt patient could safely resume treatment with estradiol.

\section{Methods}

Previously published case reports of breast neoplasia associated with GAHT have included a review component to contextualize a case within the larger body of literature on this subject, or to investigate a variable of interest. ${ }^{17-19}$ Our search built upon and expanded beyond these reviews to include recently published case reports and cases of benign breast neoplasia, identifying and adding seven new cases of breast neoplasia to those previously reviewed.

We conducted an initial literature search of the PubMed electronic database using the following combinations of general text keywords and Medical Subject Headings (MeSH) terms: ("breast neoplasms" [MeSH Terms] OR ("breast"[All Fields] AND "neoplasms"[All Fields]) OR "breast neoplasms"[All Fields]) AND ("transgender persons"[MeSH Terms] OR ("transgender"[All Fields] AND "persons"[All Fields]) OR "transgender persons"[All Fields] OR "transgender"[All Fields]). Articles were identified through multiple formal search methods, including hand searching of key journals identified during the initial search, biblio- graphic review, and citation tracking. The search was completed in multiple iterations in May and June 2017.

Only articles published in peer-reviewed journals in the English language were included. Reviews, case reports, and journal articles were included; no articles were formally excluded on the basis of study design. Eligibility criteria for studies included any report of breast neoplasia occurrence in the defined population of interest: transgender individuals receiving feminizing GAHT. Information was subsequently abstracted from each eligible case report and included the following fields: primary tumor site, age at diagnosis, risk factors for breast cancer (in particular, family history, and BRCA status), hormone receptor status (including estrogen, progesterone, and HER2 receptors), and GAHT use (including means of administration, dose, and duration).

\section{Results}

We identified a total of 22 cases of breast neoplasia among transgender individuals receiving feminizing hormone therapy for gender transition. Of these, 18 were cases of breast cancer (Table 1), and 4 were cases of benign breast tumors (Table 2). The most common cancerous tumor type identified was invasive ductal carcinoma $(n=10),{ }^{17-26}$ followed by ductal carcinoma in situ $(n=3),{ }^{17,20,27}$ and invasive adenocarcinoma $(n=2) .^{24,28}$ One case of each of the following types was also identified: secretory breast carcinoma, ${ }^{29}$ one case of poorly differentiated carcinoma in lymph nodes (with probable but unconfirmed breast origin), ${ }^{18}$ and one case of metastatic breast cancer of unknown tumor type. ${ }^{26}$ The three cases of benign breast tumors included a case of lobular hyperplasia with focal pseudoangiomatous stromal hyperplasia, ${ }^{30}$ two cases of fibroadenoma, ${ }^{31,32}$ and one case of angiolipoma. ${ }^{33}$

The average age at diagnosis for all included cases of breast neoplasia was 48 years ( \pm 11.7 , range: $30-71$ ). Risk factors for breast cancer were not consistently reported across studies, however, nearly half of the sample had some family history of cancer $(n=9)$, and of these individuals, five had a family history of breast cancer. Due to the fact that some of the included individuals used hormone therapy intermittently or for poorly defined periods of time, average duration of use was not calculated. Duration of hormone therapy ranged from $\sim 1$ year to over 30 years. With regard to hormone receptor status, the greatest number of individuals for whom information was available were ERpositive ( $n=9 ; n=6$ ER-negative; $n=7$ not reported), PR-negative ( $n=8 ; n=6$ PR-positive; $n=8$ not reported), 
and HER2-negative ( $n=7 ; n=2$ HER2-positive; $n=10$ not reported). The majority of individuals were not tested for the BRCA genetic mutation $(n=18)$. Of those tested, one individual was BRCA2-positive, and three individuals were BRCA-negative.

\section{Discussion}

Myofibroblastoma in the context of GAHT

We present the first case of a rare MFB in a transgender patient receiving feminizing estrogen therapy. This case is unique, not only because of the tumor type and ER positivity but also because of the tumor's development in the setting of GAHT. Age at tumor diagnosis (76 years) is consistent with the peak frequency distribution of male breast cancer documented in the literature (71 years). ${ }^{34,35}$ This is significantly higher than the average age at tumor diagnosis for the 22 previously reported cases of breast neoplasia in this population (48 years \pm 11.7 ). To our knowledge, this is also the first reported case of breast neoplasia associated with GAHT exclusively administered via the estradiol patch.

The three previously reported cases of benign breast neoplasia in transgender patients represent tumors that are rare if not exceptional in birth-assigned males. ${ }^{31-33}$ Myofibroblastoma, in contrast, occurs most commonly in elderly men, ${ }^{9}$ but this particular case is distinguished by its rapid onset following hormone therapy. Of the three previously reported cases of benign breast neoplasia in transgender patients, fibroadenomas were diagnosed in two patients, ages 41 and 35 at diagnosis, after about two decades of GAHT. ${ }^{31,32}$ Our case more closely resembles the third previously documented case of benign breast neoplasia, angiolipoma, which occurred in a 61-year-old FtM transgender patient following only 18 months of GAHT. ${ }^{33}$ Our case presentation was consistent with past reports of myofibroblastoma occurring in cisgender males. ${ }^{5,9}$

Research has implicated several risk factors in breast neoplasia pathophysiology among cisgender males, including the BRCA gene mutation, family history, androgen deficiency, and estrogen exposure. ${ }^{36}$ The patient had no family history of cancer and no risk factors for cancer other than former smoking (40 years prediagnosis) and estrogen exposure.

Short-term effects of hormone therapy on breast neoplasia in transgender patients

The evidence base concerning adverse effects of shortand long-term hormone therapy in terms of breast neo- plasia is limited. Wierckx et al. presented results from a multicenter year-long prospective study $(N=106)$, during which 53 transwomen received either $50 \mathrm{mg}$ cyproterone acetate and $4 \mathrm{mg}$ estradiol valerate daily $(<45$ years of age) or $50 \mathrm{mg}$ cyproterone acetate and $100 \mu \mathrm{g} / 24 \mathrm{~h}$ transdermal $17-\beta$ estradiol ( $>45$ years of age) ${ }^{37}$ No deaths or adverse events were observed. The authors concluded that the treatment modalities evaluated were both effective and low risk at short-time follow-up. Kanhai et al. studied short- and long-term histologic effects of surgical and chemical castration and estrogen therapy (50 mg cyproterone acetate twice daily and $50 \mu$ g ethinyl estradiol daily) by comparing measures from breast biopsies of 14 transgender individuals to those of 2 chemically castrated men treated hormonally for prostate cancer. ${ }^{38}$ The researchers concluded that risk of breast malignancy among transgender women receiving GAHT is likely the same or lower than the risk among cisgender women treated conservatively with estrogens. Long-term studies have reached a number of different conclusions.

Long-term effects of hormone therapy on breast neoplasia in transgender patients

A 2011 Dutch cohort study of mortality among transsexuals receiving treatment with GAHT $(N=1331$; median follow-up at 18.5 years; $100 \mu \mathrm{g}$ ethinyl estradiol daily or 2-4 mg estradiol valerate daily; and presurgical antiandrogen therapy), conducted by Asscheman et al., revealed that the overall cancer mortality rate in the $\mathrm{MtF}$ group was not significantly different from the rate in the general population. ${ }^{39}$ The observed total deaths due to malignant neoplasm $(n=28)$ did not include any cases of breast cancer, and increased overall mortality in hormone-treated participants was primarily attributed to nonhormone-related causes.

A 2013 Dutch cohort study by Gooren et al. assessed breast cancer among transgender persons $(N=3102$; $n=2307 \mathrm{MtF}$ ) between 1975 and 2011 (53,370 personyears of exposure). ${ }^{18}$ Two cases of breast cancer (one definitive and one probable) were encountered. The calculated breast cancer incidence rate, 4.1 cases per 100,000 person-years (95\% CI: 0.8-13.0), was lower than expected for cisgender females and as expected for cisgender males, and led the authors to conclude that GAHT does not seem to be associated with an increased risk of malignant breast development.

Dhejne et al. ran a 30-year retrospective cohort study from 1973 to 2003, assessing cancer mortality among Swedish transgender individuals who were birth-year matched with 10 nontransgender controls of each sex 
$\left(N=324 ; n=191\right.$ transwomen). ${ }^{40}$ Mean follow-up was 11.4 years, and 8 deaths due to neoplasms were observed (mortality rate: 2.2 deaths per 1000 personyears [95\% CI: 1.1-4.3]). The hazard ratio for cancer deaths among transgender individuals relative to nontransgender controls was 2.1 (95\% CI: 1.0-4.6). Of the deaths due to neoplasms, no breast cancers were observed, and the role of feminizing hormone therapy cannot be fully evaluated because the presented cancer data were not disaggregated by gender identity.

Wierckx et al. sought to evaluate the long-term effects of GAHT in 100 transgender individuals following gender affirming surgery in a cross-sectional study in Belgium. ${ }^{41}$ Transmen had predominantly used intramuscular testosterone $(n=35 ; 250 \mathrm{mg} / 2$ or 3 weeks), testosterone undecanoate $(n=7 ; 1000 \mathrm{mg} / 12$ weeks $)$ or transdermal testosterone gel ( $n=7,50 \mathrm{mg}$ daily). Transwomen had used transdermal 17- $\beta$ estradiol $(n=22$; $1.5 \mathrm{mg}$ daily), estradiol patch $(n=3 ; 50 \mu \mathrm{g}$ daily), or oral estrogens $(n=22)$. The included individuals had been receiving GAHT for an average of 10 years, and the authors concluded that GAHT appears to be safe in transmen. Among transwomen, however, $12 \%$ experienced a cardiovascular event during treatment. No cases of hormone-related cancer were reported.

In 2013, Wierckx et al. conducted a second crosssectional study of transgender individuals $(N=352$; $n=214$ transwomen), all of whom had received at least 3 months of GAHT with an average duration of 7.4 years. ${ }^{42}$ Trans women had used transdermal $17-\beta$ estradiol ( $n=76 ; 1.5 \mathrm{mg}$ daily), estradiol patch $(n=29 ; 50 \mu \mathrm{g}$ daily); or oral estrogens $(n=99)$. Although six cases of cancer were observed during follow-up, none was breast cancer, and the authors concluded that the prevalence of self-reported cancer among transwomen in the study was not significantly different from the prevalence in cisgender male and female control groups.

In the United States, a large cohort study of transgender veterans $(N=5135)$ by Brown et al. found an overall incidence rate of 20 breast cancer cases per 100,000 patient-years of Veterans Health Administration (VHA) treatment. ${ }^{43}$ This rate, while higher than the incidence rate documented in European studies and greater than expected for cisgender males, was comparable to the expected rate in an age-standardized national sample of cisgender females (standardized incidence ratio 1.6; 95\% CI: 0.24-7.22). In 2016, Brown et al. compared medical and mental health status of the same of veterans to corresponding data from over 15,000 nontransgender veterans matched for gender, race, birth year, and geographical re- gion. ${ }^{44}$ The prevalence odds ratio estimate for breast cancer was 0.34 (95\% CI: 0.24-0.50), suggesting a lower odds of breast cancer in the transgender veteran sample, however, matching for gender may not have been achieved. The applicability of the results of these studies to the evaluation of breast cancer risk among transgender individuals receiving feminizing GAHT is questionable, given that the studies utilized Veterans Administration Vital Status Files for demographic information and lack reliable assigned sex and gender identity information.

Adverse effects of long-term hormone therapy in the United States have been documented in studies of both transgender and cisgender women. Two large-scale studies of cisgender women in the United States and the United Kingdom have investigated the effects of specific types of hormone therapy on cancer risk. The Women's Health Initiative randomized controlled primary prevention trial evaluated the risks and benefits of estrogen plus progestin treatment in healthy postmenopausal women in the United States $(N=16,608)$ and found that combined estrogen and progestin treatment increases breast cancer risk. ${ }^{2}$ Indeed, the authors calculated a $26 \%$ excess of breast cancer at an average followup of $\sim 5$ years (crossing the monitoring boundary), which equates to 8 more invasive breast cancers over 1 year among 10,000 women taking estrogen plus progestin. The group concluded that the overall health risks exceeded benefits, and the trial was cut short of its planned 8.5-year duration.

The Million Women Study in the United Kingdom investigated the effects of hormone therapy on both incident and fatal breast cancer. ${ }^{1}$ About half of the total sample ( $N=1,084,110$, age range: $50-64)$ had used hormone therapy, and the study collaborators concluded that current users of hormone therapy were more likely than never users both to develop breast cancer and to die from breast cancer. It was estimated that $\sim 20,000$ extra breast cancers may be attributed to the use of hormone therapy over the last 10 years by women ages $50-64$ years in the United Kingdom.

These studies paint a complicated picture of the relationship between GAHT and breast cancer. There is even less evidence on benign mammary neoplasia and the role of GAHT in its development.

\section{Limitations of Current Evidence}

The relationship between feminizing GAHT and breast neoplasia is both complex and controversial, as demonstrated by the aforementioned studies and cases included in this review. Risk of breast cancer among transgender 
individuals receiving feminizing GAHT likely depends on a number of variables, including predisposing factors that have been implicated in cancer pathophysiology, as well as dose, means of administration, and duration of exposure. Existing studies are limited by a lack of documentation of risk factors, short times to follow-up that may be insufficient to see cancer development, and inadequate sample sizes limiting statistical power and the ability to detect rare events such as cancers.

The lack of evidence from large-scale, long-term, statistically rigorous studies investigating lifetime adverse events associated with GAHT has important implications. The paucity of research in this area has contributed to a lack of consensus surrounding screening guidelines for transgender patients on feminizing regimens, and we lack research evaluating the specific utility of mammography screening, in particular, in this population. Until such a time as adequate evidentiary support is available, current recommendations for breast cancer screening, including those put forth by the Center of Excellence for Transgender Health ${ }^{45}$ should be followed to promote early detection and treatment.

\section{Conclusion}

Defining the risk of neoplasia on GAHT is a priority for transgender medical and healthcare research. ${ }^{46}$ The limitations of the existing evidence base on long-term administration of GAHT and the potential role of exogenous estrogen administration as a risk factor for breast cancer in the transgender population, as evident in the mere 22 cases of breast neoplasia included in this review, is cause for concern. Cases of breast cancer in this population are rare, but often diagnosed at advanced stages. This novel report of the development of a rare MFB in the setting of GAHT suggests the need for additional reporting of MFB and other tumors presenting in transgender individuals treated with feminizing hormones and underscores the need for additional high-quality research to clearly define risks and inform clinical practice.

\section{Author Disclosure Statement}

No competing financial interests exist.

\section{References}

1. Beral V. Breast cancer and hormone-replacement therapy in the Million Women Study. Lancet. 2003;362:419-427.

2. Rossouw JE, Anderson GL, Prentice RL, et al. Risks and benefits of estrogen plus progestin in healthy postmenopausal women: principal results from the Women's Health Initiative randomized controlled trial. JAMA. 2002:288:321-333.
3. What Are the Key Statistics About Breast Cancer in Men? American Cancer Society. 2017. Available at: www.cancer.org/cancer/breast-cancer-inmen/about/key-statistics.html (accessed June 17, 2017).

4. Siegel RL, Miller KD, Jemal A. Cancer statistics, 2017. CA Cancer J Clin. 2017;67:7-30.

5. Metry M, Shaaban M, Youssef M, Carr M. Myofibroblastoma of the breast: literature review and case report. Case Rep Oncol Med. 2016;2016: 1714382.

6. Magro G, Michal M, Bisceglia M. Benign spindle cell tumors of the mammary stroma: diagnostic criteria, classification, and histogenesis. Pathol Res Pract. 2001;197:453-466.

7. Magro G. Mammary myofibroblastoma: a tumor with a wide morphologic spectrum. Arch Pathol Lab Med. 2008;132:1813-1820.

8. Tavassoli FA, Devilee P. World Health Organization Classification of Tumours-Pathology and Genetics of Tumours of the Breast and Female Genital Organs. Lyon, France: IARC Press, 2003, pp. 91-92.

9. Wargotz ES, Weiss SW, Norris HJ. Myofibroblastoma of the breast: sixteen cases of a distinctive benign mesenchymal tumor. Am J Surg Pathol. 1987;11:493-502.

10. Magro G, Longo FR, Salvatorelli L, et al. Lipomatous myofibroblastoma of the breast: case report with diagnostic and histogenetic considerations. Pathologica. 2014;106:36-40.

11. Magro G, Fraggetta F, Torrisi A, et al. Myofibroblastoma of the breast with hemangiopericytoma-like pattern and pleomorphic lipoma-like areas. Report of a case with diagnostic and histogenetic considerations. Pathol Res Pract. 1999;195:257-262.

12. Magro G, Michal M, Vasquez E, Bisceglia M. Lipomatous myofibroblastoma: a potential diagnostic pitfall in the spectrum of the spindle cell lesions of the breast. Virchows Arch. 2000;437:540-544.

13. Mele M, Jensen V, Wronecki A, Lelkaitis G. Myofibroblastoma of the breast: case report and literature review. Int J Surg Case Rep. 2011;2:93-96.

14. Magro G, Bisceglia M, Michal M. Expression of steroid hormone receptors, their regulated proteins, and bcl-2 protein in myofibroblastoma of the breast. Histopathology. 2000;36:515-521.

15. Morgan MB, Pitha JV. Myofibroblastoma of the breast revisited: an etiologic association with androgens? Hum Pathol. 1998;29:347-351.

16. Gocht A, Bosmuller HC, Bassler R, et al. Breast tumors with myofibroblastic differentiation: clinico-pathological observations in myofibroblastoma and myofibrosarcoma. Pathol Res Pract. 1999;195:1-10.

17. Maglione KD, Margolies L, Jaffer S, et al. Breast cancer in male-to-female transsexuals: use of breast imaging for detection. AJR Am J Roentgenol. 2014;203:W735-W740

18. Gooren $\sqcup$, van Trotsenburg MA, Giltay EJ, van Diest PJ. Breast cancer development in transsexual subjects receiving cross-sex hormone treatment. J Sex Med. 2013;10:3129-3134.

19. Teoh $\mathrm{ZH}$, Archampong D, Gate T. Breast cancer in male-to-female (MtF) transgender patients: is hormone receptor negativity a feature? BMJ Case Rep. 2015.

20. Symmers WS. Carcinoma of breast in trans-sexual individuals after surgical and hormonal interference with the primary and secondary sex characteristics. Br Med J. 1968;2:83-85.

21. Pritchard TJ, Pankowsky DA, Crowe JP, Abdul-Karim FW. Breast cancer in a male-to-female transsexual. A case report. JAMA. 1988;259:2278-2280.

22. Ganly I, Taylor EW. Breast cancer in a trans-sexual man receiving hormone replacement therapy. Br J Surg. 1995;82:341.

23. Pattison ST, McLaren BR. Triple negative breast cancer in a male-tofemale transsexual. Intern Med J. 2013;43:203-205.

24. Gooren $L$, Bowers M, Lips $P$, Konings IR. Five new cases of breast cancer in transsexual persons. Andrologia. 2015;47:1202-1205.

25. Sattari M. Breast cancer in male-to-female transgender patients: a case for caution. Clin Breast Cancer. 2015;15:e67-e69.

26. Brown GR. Breast cancer in transgender veterans: a ten-case series. LGBT Health. 2015;2:77-80.

27. Corman V, Potorac I, Manto F, et al. Breast cancer in a male-to-female transsexual patient with a BRCA2 mutation. Endocr Relat Cancer. 2016;23: 391-397.

28. Dhand A, Dhaliwal G. Examining patient conceptions: a case of metastatic breast cancer in an African American male to female transgender patient. J Gen Intern Med. 2010;25:158-161.

29. Grabellus F, Worm K, Willruth A, et al. ETV6-NTRK3 gene fusion in a secretory carcinoma of the breast of a male-to-female transsexual. Breast. 2005;14:71-74. 
30. Tongson K, Konovalova V, Dhawan N, et al. Breast cancer suspicion in a transgender male-to-female patient on hormone replacement therapy presenting with right breast mass: breast cancer risk assessment and presentation of a rare lesion. Case Rep Oncol Med. 2017;2017:5172072.

31. Kanhai RC, Hage JJ, Bloemena E, et al. Mammary fibroadenoma in a maleto-female transsexual. Histopathology. 1999;35:183-185.

32. Lemmo G, Garcea N, Corsello S, et al. Breast fibroadenoma in a male-tofemale transsexual patient after hormonal treatment. Eur J Surg Suppl. 2003:69-71.

33. Walsh CM, Yang L, Park JM, et al. Angiolipoma of the breast in a transgender patient. Breast J. 2014;20:662-663.

34. Fentiman I. Male breast cancer: a review. Ecancermedicalscience. 2009;3: 140.

35. Fentiman IS, Fourquet A, Hortobagyi GN. Male breast cancer. Lancet. 2006:367:595-604.

36. Johansen Taber KA, Morisy LR, Osbahr AJ, 3rd, Dickinson BD. Male breast cancer: risk factors, diagnosis, and management (Review). Oncol Rep. 2010;24:1115-1120.

37. Wierckx K, Van Caenegem E, Schreiner T, et al. Cross-sex hormone therapy in trans persons is safe and effective at short-time follow-up: results from the European Network for the Investigation of Gender Incongruence. J Sex Med. 2014;11:1999-2011.

38. Kanhai RC, Hage JJ, van Diest PJ, et al. Short-term and long-term histologic effects of castration and estrogen treatment on breast tissue of 14 male-to-female transsexuals in comparison with two chemically castrated men. Am J Surg Pathol. 2000;24:74-80.

39. Asscheman H, Giltay EJ, Megens JA, et al. A long-term follow-up study of mortality in transsexuals receiving treatment with cross-sex hormones. Eur J Endocrinol. 2011;164:635-642.

40. Dhejne $C$, Lichtenstein $P$, Boman $M$, et al. Long-term follow-up of transsexual persons undergoing sex reassignment surgery: cohort study in Sweden. PLoS One. 2011;6:e16885.

41. Wierckx K, Mueller S, Weyers S, et al. Long-term evaluation of cross-sex hormone treatment in transsexual persons. J Sex Med. 2012;9:2641-2651.

42. Wierckx K, Elaut E, Declercq E, et al. Prevalence of cardiovascular disease and cancer during cross-sex hormone therapy in a large cohort of trans persons: a case-control study. Eur J Endocrinol. 2013;169:471-478.
43. Brown GR, Jones KT. Incidence of breast cancer in a cohort of 5,135 transgender veterans. Breast Cancer Res Treat. 2015;149:191-198.

44. Brown GR, Jones KT. Mental health and medical health disparities in 5135 transgender veterans receiving healthcare in the Veterans Health Administration: A Case-Control Study. LGBT Health. 2016;3:122-131.

45. Screening for breast cancer in transgender women. Center of Excellence for Transgender Health. 2017. Available at: http://transhealth .ucsf.edu/trans?page=guidelines-breast-cancer-women (accessed June 21, 2017).

46. Feldman J, Brown GR, Deutsch MB, et al. Priorities for transgender medical and healthcare research. Curr Opin Endocrinol Diabetes Obes. 2016;23: 180-187.

Cite this article as: O'Bryan J, Wolf-Gould C, Matsuo Y (2018)

Mammary myofibroblastoma in a transgender patient on feminizing

hormones: literature review and case report, Transgender Health 3:1, 1-9, DOI: 10.1089/trgh.2017.0026.

\section{Abbreviations Used}

DSM-5 = Diagnostic and Statistical Manual of Mental Disorders, fifth edition

$\mathrm{ER}=$ estrogen receptor

$\mathrm{GAHT}=$ gender-affirming hormone therapy

$\mathrm{MFB}=$ mammary myofibroblastoma

$\mathrm{PASH}=$ pseudoangiomatous stromal hyperplasia

$\mathrm{PR}=$ progesterone receptor

$\mathrm{SMM}=$ smooth muscle myosin

$\mathrm{VHA}=$ Veterans Health Administration

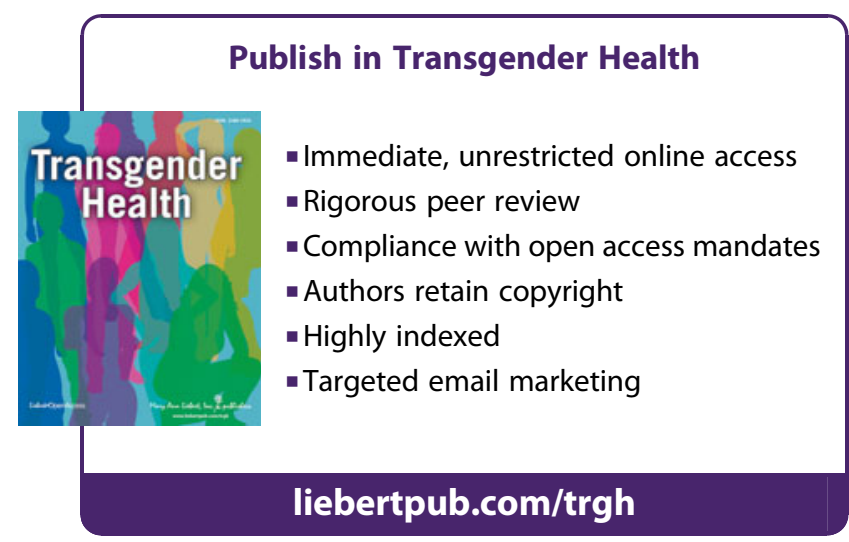

